\title{
Review of a community-based youth counselling service in Ireland
}

\author{
Kevin Lalor ${ }^{\mathrm{a}, *}$, Sinead O'Dwyer ${ }^{\mathrm{b}}$, Denis McCrann ${ }^{\mathrm{a}}$ \\ a Department of Social Sciences, Dublin Institute of Technology, 40-45 Mountjoy Square, Dublin 1, Ireland \\ ${ }^{\mathrm{b}}$ Kildare Youth Services, Ireland
}

Received 15 December 2004; received in revised form 9 April 2005; accepted 14 April 2005

Available online 24 June 2005

\begin{abstract}
The structure and operation of a community-based youth counselling service operated by the Kildare Youth Services (KYS), Ireland, are examined with a view to highlighting the preventative nature of such a service. Presenting problems are explored, in the context of the wider social milieu. Particularly, recent trends in sexual behaviour, substance abuse and child sexual abuse are examined. Interviews were conducted with a sample of professionals who referred clients, patients and students to the KYS Youth Counselling Service. Interviews were also conducted with a small sample of clients of the service and with the counsellor-coordinator of the Youth Counselling Service. The service was viewed positively throughout the community and its role in the prevention of further distress was highlighted.

(C) 2005 Elsevier Ltd. All rights reserved.
\end{abstract}

Keywords: Community-based youth counselling service; Kildare Youth Services; Ireland

\section{Introduction}

This paper describes the workings of a community-based youth counselling service, as operated by the Kildare Youth Services (KYS). County Kildare is in the eastern part of Ireland, adjoining Co. Dublin. Settlement patterns are largely rural and small towns in the

\footnotetext{
* Corresponding author. Tel.: +35314024163.
}

E-mail address: kevin.lalor@dit.ie (K. Lalor). 
south, and larger dormer towns in the north of the county, which is in the commuter belt of Dublin City. The aim of the paper is to describe clients' presenting problems, to consider the wider social context within which these difficulties arise and to emphasis the preventative nature of community-based youth counselling.

Young people in Ireland face particular difficulties today; underage drinking in Ireland is the highest in Europe, suicide rates amongst young males have increased dramatically in recent years and unwanted sexual experiences amongst adolescent girls are commonplace. The economic, political, technological and cultural transformation of the past decade has undoubtedly influenced and aided the development of these worrying trends. This paper suggests that community-based youth counselling services are an important provision in the care of Ireland's young people and serve as a preventative measure which may pay high dividends in years to come.

The Kildare Youth Services Youth Counselling Service operates in the context of a rapidly growing youth population with increased levels of young lone parents, youth suicide, drug misuse and family breakdown. The changes that have occurred in Ireland in recent years, and the impact these have on young people, are also central to the National Youth Work Development Plan, 2003-2007 (Department of Education and Science, 2003). While a comprehensive analysis of the impact on young people of the changing socio-economic context is beyond this paper, a 'snapshot' of the primary adverse consequences (as they are presented to the Kildare Youth Services Youth Counselling Service) is provided. This is followed by a description of the Kildare Youth Services Youth Counselling Service, an analysis of presenting problems to the service and, finally, a description of a recent needs analysis of the Kildare Youth Services Youth Counselling Service.

\subsection{Alcohol and substance abuse}

A European School Survey Project on Alcohol and Other Drugs report (ESPAD) (Hibell et al., 1997) indicated that 23\% of Irish adolescents (1849 fifth year students were surveyed) reported 'binge drinking' (more than five drinks in a row). This was the highest figure for binge drinking amongst adolescents surveyed in 26 European countries. With regard to lifetime prevalence of cannabis, amphetamines, LSD, crack cocaine, ecstasy and heroin, Irish adolescent usage was also amongst the highest, at 37\% (by way of contrast, the lowest figures were for Malta, at $2 \%$ ).

A follow-up ESPAD report (Hibell et al., 2000) has confirmed this trend, with Irish 1516 year olds ranked in the top three of 30 nationalities for binge drinking, being drunk over a 12-month period and using cannabis. Between the two data collection dates (1995 and 1999), the proportion of teenagers drunk three or more times in the previous 30 days increased from $15 \%$ to $24 \%$.

Also, Irish teenagers were most likely to 'binge drink' (five drinks or more), with almost one third of Irish teenagers binge drinking three times or more in the previous 30 days.

A study of 10-12 year olds in Dublin (Brinkley, Fitzgerald, \& Greene, 1998) found a lifetime prevalence of 'any illicit substance' of just under $33 \%$, cannabis being the most commonly used. This same survey found that $16 \%$ of $10-12$ years olds sampled reported 
regular drinking and the same number reported daily smoking. Compared to four other European cities where this survey was conducted (Newcastle Upon Tyne, Groningen, Rome and Bremen), rates of alcohol and illicit substances were high. Also, the availability of illegal substances was highest in Dublin (Brinkley et al., 1998).

A Garda (Irish police Force) survey (Sarma, Walker, \& Ryan, 2002) of 3040 2nd and 5 th year pupils in Waterford, Kilkenny and Kerry schools revealed that $24 \%$ were considered smokers, $39 \%$ had been drunk in the preceding month and $23 \%$ were found to have taken drugs in their lives.

An epidemiological study of the nature and incidence of drug use amongst the secondary school population of County Kildare and West Wicklow was conducted by the Eastern Health Board (1999) (Table 1).

This area has a population of 147,581 and includes the catchment area of the Kildare Youth Services Counselling Service (Naas, Newbridge and Athy). Unfortunately, the report does not present data by local areas. However, it gives an indication of the substance use amongst young people in the Kildare Youth Services Counselling Service target areas as 29 of the 31 schools in the Kildare/West Wicklow region participated.

In total, 1893 pupils between 13 and 18 were surveyed (mean age $=14.7$ years). Ninety two percent were from the Co. Kildare area. The lifetime prevalence rates for cigarettes were $67 \%$; alcohol, $81 \%$; solvents, $23 \%$; cannabis, $27.5 \%$. Between $1.5 \%$ and $5 \%$ of pupils had lifetime prevalence for other substances, including LSD, ecstasy, mushrooms and heroin. Some $90 \%$ of pupils in the 16-18 age range have taken alcohol. With regard to illicit drug use, $64 \%$ of the total sample had not used any illicit drugs; $20 \%$ had used one drug, $9.4 \%$ had used two illicit drugs and $6.6 \%$ had used three or more drugs. Significantly more males $(41 \%)$ than females $(31 \%)$ have experimented with illegal drugs $(p<0.05)$ (EHB, 1999, p. 15).

As high as these figures appear, the authors report that they are consistent with recent epidemiological work conducted in Dublin, Limerick and the Western Health Board area. Solvent use would appear to be an exception, the lifetime prevalence rate being higher in the Kildare/West Wicklow regions (23\%), than that reported in similar epidemiological studies (EHB, 1999, p. 23). They also report that experimentation with drugs does not, in most cases, lead to addiction.

In summary, legal and illegal drug use is high amongst adolescents in the KYS Youth Counselling Service catchment area. This is a pattern that repeats throughout the country.

Table 1

Percentage lifetime prevalence use of drugs by $13-18$ year olds in Kildare and West Wicklow

\begin{tabular}{lcc}
\hline & $13-15$ years, \% lifetime prevalence & 16 years,$+ \%$ lifetime prevalence \\
\hline Cigarettes & 64 & 72 \\
Alcohol & 76 & 90 \\
Cannabis & 20 & 40 \\
LSD & 1.8 & 3.4 \\
Amphetamines & 2.8 & 6.4 \\
\hline
\end{tabular}

Differences significant at $p<0.05$, (extracted from EHB, 1999, p. 12). 


\subsection{Sexual behaviour}

Recent years have seen the publication of a number of surveys of the sexual experiences of young people in Ireland. MacHale and Newell (1997) found that 21\% of a sample of 2754 pupils aged 15-18 had had sexual intercourse, with boys more than twice as likely as girls to have had sexual intercourse. The mean age of first sexual intercourse was 15.5 years. Similarly, Alliance (1997) surveyed $80015-24$ year olds and found that 22\% of females and $32 \%$ of males had their first sexual intercourse experience by the age of 16 . Over half of MacHale and Newell's respondents who had had sexual intercourse stated that the first time they had sex was with a 'casual' partner, with 35\% claiming that alcohol and $9 \%$ claiming that non-prescribed drugs were a contributory factor. Some $72 \%$ of the participants reported using a condom the first time they had sexual intercourse, but of the 475 pupils who had sex regularly only $67 \%$ used condoms 'all the time' with $33 \%$ 'sometimes' or 'never' using condoms. Although there was generally a high level of sex education knowledge within the group, over one third of the sexually active respondents had been involved in high-risk behaviour.

Lalor, O' Regan, and Quinlan (2003) found a less disturbing picture. In a survey of 247 college students they found that only $12 \%$ of participants had experienced consensual sexual intercourse before the age of 16 years, the frequency of intercourse increasing with age. Respondents from Dublin city or county were more likely to report having sexual intercourse than respondents from rural areas. Males were more likely to report than females. The chaste nature of boyfriend/girlfriend relationships in the 18-20 age grouping was also observed.

Note that while comparative data are not available, and while sexual activity amongst young people is hardly a recent phenomenon, it seems reasonable to suggest that young people are more likely to be sexually active than was the case in the past.

\subsection{Sexual abuse}

The Sexual Assault and Violence in Ireland (SAVI) report (McGee, Garavan, de Barra, Byrne, \& Conroy, 2002) provides the first nationwide survey of childhood sexual abuse. It was found that 1 in 5 women reported experiencing contact sexual abuse in childhood with a further 1 in 10 reporting non-contact sexual abuse. In over a quarter of cases of contact abuse, the abuse involved penetrative sex-either vaginal, anal or oral sex. One in six men reported experiencing contact sexual abuse in childhood with a further 1 in 14 reporting non-contact sexual abuse. In one of every six cases of contact abuse the abuse involved penetrative sex-either anal or oral sex.

In terms of non-consensual sexual experiences amongst Irish adolescents Lalor (1999) reported that:

- $31.8 \%$ of the female sample and $5.6 \%$ of the male sample had an unwanted sexual experience before the age of 16 .

- $23.9 \%$ of the female sample has experienced an unwanted sexual episode prior to their teenage years. When episodes of indecent exposure are excluded, we find that $15.34 \%$ of the female sample has experienced contact sexual abuse prior to their 13th birthday. Corresponding figures for male respondents are considerably smaller. 
- $10.25 \%$ of the female sample and $2.8 \%$ of the male sample have endured unwanted sexual experiences over a period of months or years prior to their 16th birthday.

- Whilst under 16 years of age, respondents were significantly more likely to experience unwanted kissing, attempted intercourse, intercourse, masturbation and oral sex with somebody younger than 21 years, as compared to somebody 21 years or older.

It is to be hoped that we are witnessing a rise in reporting rates rather than incidence rates. In order for us to monitor whether this is the case, on-going, periodic epidemiological work is justified in Ireland to ascertain at which level reporting rates for child sexual abuse shall peak.

\subsection{Early school leavers}

In a review of the Newbridge Community Training Workshop (CTW), Fleming and Kenny (1998) identify early school leavers as a group likely to have significant counselling needs. They surveyed 247 early school leavers in the Naas, Newbridge, Monasterevin, Kildare, Clane, Curragh, Rathangan, Kilcullen (mid-Kildare) area who had left school early in the years 1995-1996. They note the high incidence of drugs, violence, sexual abuse, early parenthood and family dysfunction amongst trainees. Whilst acknowledging that a 'listening ear' may suffice for day to day issues and concerns, they note in their review that the gravity of some issues and the depth of hurt felt by these young people warrant professional counselling and that CTW services should have qualified, full-time counselling staff and that counselling should be a key area of work for CTWs (p. 24). Since Fleming and Kenny's (1998) report, Newbridge CTW has employed a part-time counsellor.

\subsection{Social needs of young people: Kildare Town}

A study examining the social needs of young people was conducted recently in Kildare Town by Action South Kildare and Kildare Youth Services. The purpose of the report was to examine "the extent of youth disadvantage and the needs of young people in Kildare Town" (Stapleton, 2000, p. 4) and, as such, gives a valuable insight into the issues for young people in this area. The report is an impressive audit of youth services and facilities in the entire town. It also details young peoples' perceptions of these services and their various suggestions. The report contains some interesting demographic information. For example, the 1996 census indicates that $21.2 \%$ of family units in Kildare town are headed by a lone parent. This is double the average in the County as a whole (approximately 10\% of households in the County are headed by a single parent, according to the 1996 census) (Fleming \& Kenny, 1998, p. 11). Thus, Kildare town's level of single parent households is $100 \%$ greater than the average in the rest of the County.

One hundred young people completed a questionnaire as part of this study (34 males and 66 females), ranging in age from 10 to 19 years. When asked to describe the problems teenagers in the town experience, 75\% said 'drugs,' $42 \%$ said 'alcohol' and $38 \%$ said 'boredom, nothing to do.' Smaller numbers of respondents reported a range of other issues, but these three were by far the most frequently cited problems. As per the reports we have examined earlier, drug and alcohol use are significant issues for young people in Co. Kildare. 


\subsection{Social needs of young people: Newbridge}

The 1998 action plan for Newbridge Community Development noted the great concern for young people expressed by all participants in its consultative process. Lack of facilities was identified as a major problem. "The problems of alcohol and drug abuse were identified by all sectors of the community" (Newbridge Community Development Group, 1998, p. 71). The need for a counselling service, as expressed by young people, was also noted: "Youth spoke of a need for some kind of confidential service that would allow them to speak of matters which they otherwise find it difficult to talk [about]" (p. 71).

The action identified by Newbridge Community Development was to direct existing youth counselling services in the County to Newbridge. To an extent, this has now occurred, as the Kildare Youth Services Youth Counselling Service operates in Newbridge for $3 \frac{1}{2}$ days a week. Clearly, however, the level of need identified by the Newbridge Community Development Action Plan is not being met with this limited degree of cover.

\subsection{Social needs of young people: North Offaly and West Kildare}

In a survey of the needs of rural youth in North Offaly and West Kildare, Fitzgerald (1997) notes that many of his respondents reported feelings of isolation, loneliness and depression. The author notes the apparent higher susceptibility of rural dwellers to suicide. Indeed, Fitzgerald (1997) recommends that the KYS Youth Counselling Service be extended to the North Offaly and West Kildare area to combat the issues of loneliness and isolation for young people. To date, as we have seen, this expansion of the service has not occurred.

\subsection{Needs of young people in the Kerry Diocesan Youth Service area}

Whilst geographically removed from Co. Kildare, it might be instructive to review a recent report on the needs of young people in another, largely rural, region: Co. Kerry (O’Dwyer, 2001).

Again, the issues of boredom, isolation, lack of access to services and lack of contact with peers were cited as particular problems for rural youth. The author reiterates the need for an accessible counselling service to back up rural youth work and cites similar recommendations from studies in other parts of the country; McGowan (1997) and Smith (1998) (Edenderry and Tullamore, respectively):

"Both concluded that rural young people should have access to a locally based counselling service, which had close links with and complemented the local youth service provision" (O’Dwyer, 2001, p. 39).

In summary, a range of serious issues challenge the well being of young people in County Kildare, including drug and alcohol use, early sexual behaviour and lack of facilities. Few deem the available facilities and services adequate.

In some cases, these issues have been quantified by use of epidemiological surveys. In others, it is the perception of people on the ground in communities throughout Co. Kildare. What appears clear is that adolescent and young people in contemporary Ireland are coming of age in a complex, challenging environment with fewer certainties than heretofore. The 
problems of suicide and parasuicide are also inextricably linked to these growing problems faced by young people. According to the National Suicide Research Foundation Annual Report (2002), most parasuicides are carried out by young people, for females the peak age is 15-19, and for males 20-24. The high figure for males in particular is worrying and is yet another indicator for the establishment of community-based counselling services.

\section{The KYS Youth Counselling Service}

Kildare Youth Services have been working since 1994 at developing a communitybased, accessible, professional Counselling Service to meet the needs of young people and their families in County Kildare. To this end, Kildare Youth Services, in partnership with the South Western Area Health Board and with additional funding from the Department of Social and Family Affairs have worked to develop a tailor-made service focussing directly on the kinds of supports which are often only accessible to people on a fee paying basis.

The Counselling Service has to-date expanded to eight towns throughout County Kildare. This follows the completion of phase 1 of an expansion plan put forward to the South Western Area Health Board in 2001. The main focus of the service is targeting young people at risk, with emphasis on areas of high disadvantage, such as young people from marginalised areas where there is low educational attainment, high unemployment and high crime rates. The Counselling Service is a free service and is available to young people from across the socio-economic spectrum.

The mission statement of the counselling service is:

"to provide a professional, accessible, preventative counselling, education, information service to young people (11-25 years), their families and communities in County Kildare".

\subsection{Community-based}

A particular strength of the counselling service is that it is embedded in existing community services. Young people use the KYS for a variety of purposes and can encounter the counselling service in this way. This is thought to be considerably more user friendly and less intimidating than other services. For example, KYS operates a youth information service, youth projects, an early school leaver's programme, the Naas Child and Family Project, as well as a number of youth clubs.

A primary strength of the service is its embeddedness in the community; that it is integrated into an existing community-based service. This allows 'infiltration' to parts of the community that other counsellors would have little access to. Also, clients can be referred to other key groups, such as Young Women's Groups, Young Men's Groups and The Information Service. As part of an existing youth-focused service, it is less intimidating and more attractive to the target age group than other services. The counsellors work in very creative ways with young people using a broad range of therapeutic approaches. The wide variety of training and experience of the team creates a dynamic and eclectic approach which 
facilitates the development of a new working model for counselling young people in a community setting.

\subsection{A professional service}

The Youth Counselling Service operates on a professional basis. This is an important feature, given the absence of statutory registration for psychologists, therapists and counsellors in Ireland. All counsellors of the Kildare Youth Services Youth Counselling Service meet professional standards of accreditation or registration with one of the following counselling bodies: the Irish Association of Counselling and Psychotherapy (IACP), the Irish Association for Humanistic and Integrative Psychotherapy (IAHIP) or the Psychological Society of Ireland (PSI). All counsellors/psychotherapists of the service engage in approximately 5 -h supervision per month and attend their own personal psychotherapy on a needs-be basis:

"The issue of self care for each counsellor is recognised as very important in being able to deliver effective counselling to our clients. To this end, the team support, our own personal therapy, our commitment to on-going training and supervision are crucial in terms of the healthy and on-going professional development of this service" (KYS Youth Counselling Service Annual Report, 2003, p. 25).

On contacting the service all clients are offered an appointment (or in areas where demand is very high their details are taken and added to the waiting list for that area). An information pack about the Youth Counselling Service is sent to parents and young people at this stage. This includes parental consent forms (u18 years), confidentiality forms, information about counselling at KYS, charter of rights for clients, complaints procedure and important contact numbers. Clients are invited to ring at any stage to check where they are on the waiting list until an appointment becomes available.

The fact that a professional service is available free of charge is a considerable strength of the service, allowing access to accredited counsellors/psychotherapists by those who otherwise might not be able to afford it.

\subsection{Staffing}

The Counselling Service team presently consists of the Counsellor Coordinator, the Counselling Administrator, three full-time Youth Counsellors and a sessional Youth Counsellor. The team meets weekly for on-going training, supervision and Coordination of target areas. The varied backgrounds of the team provide an interesting and dynamic team environment and the strong focus on creative therapeutic approaches lends well to working with young people. All full-time accredited counsellors see 16 clients a week with that number increasing for those involved in group counselling. Other time is spent on training and development; counsellors attend relevant courses and workshops throughout the year. 


\subsection{Clinical/peer/management supervision}

The importance of supervision for Counselling staff is reflected in a three-tier supervision is in place for all Counsellors. This includes:

1. Group peer supervision-4 h per month.

2. External one-to-one clinical supervision-1 h per month.

3. Management one-to-one supervision $-2 \mathrm{~h}$ per month.

Each counsellor attends for external clinical supervision with a more experienced accredited counsellor on a monthly basis. Group peer supervision also takes place on a bimonthly basis. The purpose of these varied types of supervision is to ensure that the counsellor evaluates his/her work on an on-going basis with the aim of providing the best possible professional service to clients.

Management supervision is carried out between the Counsellors and the Service Coordinator at least once a month. These are supported by monthly reports submitted by each Counsellor out-lining the work in their target areas. The Coordinator reports back to the Regional Director and meets with her at least once a month for managerial supervision. This allows for review, development, planning and evaluation of each person's role in the Service and within the overall plan of Kildare Youth Services.

\subsection{Location}

The Counselling Service provides a service in the following locations: Naas, Newbridge, Athy, Celbridge, Leixlip, Kilcock, Kildare town and the Curragh. All the rooms used by the Service have been selected due to their central community-based location and their easy access. Three of the services are located in the same building as the Kildare Youth Services projects, that is, Naas, Athy and the Curragh. However, all referrals to the service come through the main office at Canal Stores, Basin St., Naas. Clients' details are taken and passed on to the appropriate counsellor.

\subsection{Referral sources}

As we can see in Table 2, the largest source of referrals was "family members". The high 'self' referral figure demonstrates that young people are accessing the service themselves, which is a positive sign in terms of access to the service. School referrals are up on previous years as are referrals from Community workers, G.P.s, Probation Service, Juvenile Liaison Officers, Child Guidance, South Western Area Health Board and Kildare Youth Services. This broad referral base indicates that the service is a recognised provider of care for young people in the area.

\subsection{Combined presenting problems to the Kildare Youth Services Youth Counselling Service}

Young people present to the Youth Counselling Service with a wide variety of difficulties. In Table 3, the 'combined presenting problems' for 2003 are detailed. This is 
Table 2

Referral sources for new clients, 2003

\begin{tabular}{lc}
\hline Referral sources & Number presenting \\
\hline Family member & 46 \\
School & 35 \\
Self & 24 \\
G.P. (General Medical Practitioner) & 22 \\
SWAHB (South Western Area Health Board) & 20 \\
JLO (Garda [Police] Junior Liaison Office) & 14 \\
Probation service & 11 \\
Community worker & 10 \\
Friend & 3 \\
NCFP & 3 \\
KYS (Kildare Youth Services) & 3 \\
Child guidance & 3 \\
Past client & 2 \\
STrter & 2
\end{tabular}

Source: KYS Youth Counselling Service Annual Report, 2003.

defined as the problem, or issue, as judged by the counsellor and may differ from the 'presenting problem'; that is, the initial issue raised by the client. The number of clients presenting has increased three-fold since 2001 in line with the expansion undergone by the Kildare Youth Services. Behavioural problems, self-esteem, family relationships and parental issues are major sources of difficulty for clients availing of the service. A host of other issues also occurs. Of course, a single client may experience a number of the categories listed in Table 3.

The Youth Counselling Service is offered to clients of the ages between 11 and 25 years and their families. In 2003 a total 170 clients were offered appointments. Of these new clients, 50 were young females, 43 were young males, 50 were adult males and 27 were adult females. Seventy-nine parents of clients were engaged with the Service. The increase in the number of young males availing of the service is especially positive.

\subsection{Requests for counselling outside target areas}

A total of 43 requests from 23 locations including the surrounding counties of Meath and South County Dublin outside the Kildare Youth Services target area have requested counselling for young people. This would suggest the need for similar services in other counties to meet their needs and highlights the known effectiveness of the Kildare Youth Services counselling service outside the county of Kildare.

\section{Methodology and sample}

In 2001, a needs assessment of youth counselling in County Kildare was conducted (KYS, 2001). Data was collected by means of interviews with a sample of professionals who refer clients, patients and students to the Kildare Youth Services Counselling Service. These professionals consisted of four Social Workers, four Principals or Guidance 
Table 3

Combined presenting problems of counselling service clients, 2003

\begin{tabular}{lll}
\hline Combined presenting problem & Number presenting $(N=342)$ & As a \% of total \\
\hline Behavioural problems & 52 & 17 \\
Family relationship problems & 51 & 17 \\
Self-esteem & 34 & 11 \\
Parenting issues & 33 & 11 \\
Parental separation & 29 & 10 \\
Bereavement & 20 & 7 \\
Depression & 17 & 6 \\
Bullying & 16 & 5 \\
Physical abuse & 13 & 4 \\
Family member alcoholic/addict & 10 & 3 \\
Substance abuse & 9 & 3 \\
Suicidal thoughts & 8 & 3 \\
Attention deficit disorder & 7 & 2 \\
Foster care issues & 7 & 2 \\
Alcohol related problems & 6 & 2 \\
Peer/romantic relationship problems & 6 & 2 \\
Family of child sexual abuse & 5 & 2 \\
Self-mutilation & 5 & 2 \\
Suicide attempt & 4 & 1 \\
Sexual abuse & 4 & 1 \\
Adoption & 3 & 1 \\
Sexual issues & 1 & 0.3 \\
Teenage pregnancy & 1 & 0.3 \\
Compulsive obsessive disorder & & 0.3 \\
\hline Tot & 1 & 5 \\
\hline
\end{tabular}

\footnotetext{
a Total greater than $100 \%$ due to multiple presenting problems. Source: KYS youth Counselling Service Annual
} Report, 2003.

Counsellors, two General Practitioners and a Probation Officer. Interviews focused on the perceived need for a dedicated counselling service in the County, current referral practices and recommendations for future service provision.

Interviews were also conducted with a small sample (5) of clients of the service. This included two adolescents and three mothers of children using the service. Interviews focused on initiation to the service, perceptions of the service, recommendations for the service and youth issues generally.

The counsellor-coordinator of the Youth Counselling Service was also interviewed.

\section{Results}

The results shall be presented as follows. Firstly, the interviews with referral agents are described; secondly, interviews with service users are reported; thirdly, the contents of 30 client evaluation forms are presented and, finally, the interview with the Kildare Youth Services counsellor/coordinator is discussed. The information given derives primarily from the period October 2000 and March 2001 when the service was in the embryonic stage in its development. 


\subsection{Interviews with referral agents}

Four social workers, two school principals, two Guidance Counsellors, two General Practitioners and a probation officer were interviewed regarding the perceived need for a dedicated counselling service in County Kildare, current referral practices and recommendations for future service provision. Each of these topics shall be addressed below.

\subsubsection{Nature and incidence of referrals to the youth counselling service}

Most respondents were able to quantify quite accurately the number of referrals they make to the KYS annually. Typically, it would be in the region of five or six a year. One of the General Practitioners was unable to quantify his referrals as he made informal, verbal suggestions to his patients and he had no sense of how many of them took this advice.

A number of respondents mentioned that they are discouraged from referring patients, clients or students to the Kildare Youth Services Counselling Service because of the waiting list and, where immediate assistance is required, they will consider other options (which are discussed in greater detail below).

'Initially, I referred up to a dozen a year. Fewer this year [2001] because of the waiting list. This is a major problem. It has come to the stage where I won't even consider KYS if a problem is urgent. In contrast, a child can be at a GP within the day and see a psychiatrist within a week'.

In schools that have a career guidance Counsellor, referral to an outside counsellor is considered if

'the pupil or parents wanted an external perspective, or if the case were a very serious one or if the guidance counsellor was very busy'

'if I felt it was going to be an on-going or long term issue'.

A range of problem issues are referred to the Kildare Youth Services. These include behavioural problems, bullying, poor school attendance, shyness, issues around single parenthood, family problems, drugs/alcohol, abuse, bulimia, depression, school refusal and criminal behaviour.

\subsubsection{Professionals' perception of the Kildare Youth Services Counselling Service}

The general perception of the youth counselling service amongst a range of referring professionals in the Services' catchment area is extremely positive, as we can see from the following remarks:

'It's a very useful service and is seen as "young-people" friendly in that it doesn't have the association with authority. This independence as a service is a major strength'

'Parental feedback is that it is a useful service. Parents particularly value being met by the counsellor and they find this a source of great support in stressful times' 
'A strength of the service is that it caters for people up to age 25. This is very useful because Child Guidance will only take people up to age 16 (or 18 if they have previously engaged). After this, there is nowhere for them only adult psychiatric services. This isn't always appropriate as clients may not be psychiatric'

'The counsellor's proximity to the school is very helpful. Pupils can just pop out at lunchtime or take a class off. It's like a normal appointment. They don't need to take half a day off, or their parents don't need to take time off to bring them somewhere'

'The fact that it is free is very important. One third of pupils [Athy School] are on medical cards and simply could not afford private counselling'

'Feedback from pupils is very good, across the board. Pupils report that the counsellor is very affirming, that she gives them a strong sense of being worthwhile'

'Kildare Youth Services is more informal than Child Guidance Clinics. It's less intimidating for young people'.

As we might expect, a number of the respondents were critical of the waiting list for the service, and the limited available time in a given location:

'The Counsellor is described as very helpful and approachable by my patients, but my perception is that she is "snowed under" with work'

'A waiting list of two months is too long for the pressing problems that may present themselves in young people. For counselling young people immediacy and availability, 24 hours a day, are essential'

'When counselling young people, speed is of the essence. Motivation may only be fleeting and it's important for them to see the counsellor as soon as possible. The waiting list is too long and this stops me from referring clients. The Counselling Service needs more counsellors. It must see referred people within a week. Any longer than this is no good'

'Schools often need instant help in psychiatric/counselling issues. Issues can arise very quickly and behaviour can deteriorate very quickly. The Kildare Youth Services Counselling Service (or anyone) is rarely able to offer this. Principals should have somewhere they can go for immediate assistance, 24 hours a day. There should be some centralised system where one can get immediate, expert advice. There needs to be a "psychiatric ambulance service".

\subsubsection{Alternative referral options}

In order to assess the demand, and impact, of the Kildare Youth Services Youth Counselling Service, respondents were asked to indicate other youth counselling referral options. A number mentioned the Health Board's Child Guidance (psychiatric) services. 
This was particularly so if the respondent felt a child/young person to be in need of medication. A recurring, feature, however, was the extensive waiting list for this service. The adult psychiatric services were also used, again if the respondent felt the client was psychiatric and in need of medication. The perception was that this service was not in a position to provide extensive counselling.

Six of the ten respondents refer their clients to private counsellors and clinical psychologists from time to time. A number mentioned the importance of personal knowledge of these counsellors to feel comfortable in referring to them. A further three respondents stated that their client group is not in a position to pay for such counselling. This was particularly true of social workers' clients.

Respondents use a variety of other helping resources. For example, the Eastern Health Board (now the South Western Area Health board) addiction counsellor, the ISPCC in Kildare and even a "particularly caring and helpful" local Garda [police] sergeant.

\subsubsection{Perception of the need for a youth counselling service}

Again, the following material is based on individual perceptions. It is the collected views from social workers, GPs, career guidance teachers, school principals and a probation officer on the issues and challenges that face young people, and which can lead to trauma, distress requiring counselling/psychological intervention. Some of it is based on 20 years of experience or more, whilst some professionals have only been working a year or two in the area. However, as we shall see, a number of consistent themes emerge.

Firstly, most respondents expressed concern regarding the level of alcohol and drug use amongst young people.

The general perception amongst professionals was that young people are drinking more heavily, and at a younger age, than in the past. Also, recreational drug use is thought to be increasing. In the words of one social worker:

"I have been in Naas since 1997 and at that time it was a refreshing change from Dublin as there were so few drugs. Now, however, things have significantly deteriorated. Also, alcohol is a major problem amongst young people in Naas".

A second area of concern is the perceived increase in sexual behaviour amongst young people. GPs report prescribing 'far more' emergency contraception than in the past. Issues relating to family life and structure were also perceived to be changing. Family separation issues and child discipline dominate the caseloads of many professionals.

Finally, a number of respondents expressed concern at the effects of the recent economic growth in Ireland on the values and behaviour of young people:

'Paradoxically, the improved economy is making it more difficult for some young people to stay in school. The incentive to get an education simply is not there anymore'

'Also, young people are working now and so have money to spend. Unlike in the past, this money is not for the family but purely for their own spending. This is an unhealthy trend' 
'There is a huge pressure to have money amongst young people. They may need $£ 100$ a night and may have 2 nights like this a week. They are very materialistic, as they have been brought up in a material world'.

\subsubsection{Two other observations}

One social worker expressed reservations about referring clients to private counsellors. Quite aside from the price, she was uncertain as to the systems for accrediting such counsellors. Ireland does not yet have a system of statutory registration of counsellors or therapists and there is no doubt that this creates a doubt about standards amongst the general public. Indeed, throughout this research, it became evident that there was widespread confusion amongst social workers, teachers and GPs as to what constitutes a professional, "properly" trained counsellor or therapist.

A further comment referred to the perceived gap in psychiatric services between the Child Guidance Service (typically, Child Guidance will see children up to their 16th birthday) and the Adult Psychiatric Services (for those aged 18 years + ). A youth counselling service which would bridge this gap was considered very useful. It was seen as particularly important that the Kildare Youth Services Youth Counselling Service extends to include those between the ages of 18 and 25 , as this can be a particularly vulnerable time:

"This age group are the next generation of parents. We should look after them or their children will be the next generation of our clients!"

\subsection{Interviews with clients}

Initially, it was intended to interview five clients of the counselling service. The counsellor/coordinator approached a number of clients and explained the nature of the research. Given the vulnerability of some clients, those approached had to be judged by the counsellor to be in a position to be interviewed without upset to themselves. In total, four clients expressed their willingness to be interviewed. Two, however, subsequently withdrew before being interviewed. Thus, two clients of the Youth Counselling Service were interviewed. This number was supplemented by three further interviews with parents (all mothers) of adolescents/young people who had used the service.

It should be noted that the interviewer stressed to interviewees that the focus of the research was not the issue that brought them into counselling. Instead, the focus was on their perceptions of the service and their views as to the availability of services for young people in their area.

\subsubsection{What did the service do for you/your family?}

A number of interviewees reported that the counselling experience gave them skills and confidence to deal with the issues in their lives:

'It has made me stronger'

'It was there when I needed it' 
'It has taught me how to deal with negative feelings'

'Our 1st daughter just loved it. It brought her back to herself'

'It provided good support for the family. It brought us all together'.

Others valued the opportunity to talk to somebody about their problems and found comfort in the fact that somebody was taking their problem seriously:

'I got a great sense of relief that my child was being seen by a counsellor, finally'

'It has given me somebody I can talk to, confidentially

It's reassuring just to know it's there'

'I found it great to talk to somebody'

'Overall, a very positive experience. Good to talk to someone for an hour'

'It helped to draw me out-I've seen counsellors, social workers, accord workers before. Nobody has been any good compared to [counsellor] in dealing with me and my family's problems'.

In conclusion it is difficult to describe the anguish and worry experienced by parents of children with social or behavioural problems. However, this is something that came across very strongly in interviews with parents. Some were at 'the end of their tethers' and desperate for assistance when they first encountered Kildare Youth Services. It is hard to exaggerate the appreciation and gratitude described by parents that somebody was taking their problem seriously; this somebody being approachable and welcoming.

\subsection{Client evaluation forms}

The following section examines the evaluation forms in which clients of the Kildare Youth Services Youth Counselling Service are asked to fill in on completion of the counselling. Responses vary in complexity and insight, but are an indication of clients' feelings at the termination of counselling and provide a useful evaluation of the service from the perspective of the client. We shall consider the responses of 30 clients to each of the seven questions on the evaluation form in turn.

\subsubsection{What was the most valuable part of attending the service?}

The primary benefits of the service for clients were having somebody to listen and being affirmed in them. 
Eighteen of the clients mentioned 'the chance to talk' as the most valuable part of the service. This was expressed in a variety of ways:

'the chance to talk'

'getting things off my chest'

'a chance to get things out in the open'

'sorting things out in my head'

Being affirmed in their behaviour and feelings was identified as being the most valuable part of the service for a further eight clients. Again, this was expressed in a variety of ways:

'Confirmed that I wasn't wrong to feel this way'

'Made me feel good about myself'

'Helped us to accept that we are doing the best we can'

'Realised I wasn't the only one to feel this way'

'Helped me to look at things differently'

'Helped me to develop a positive attitude'.

Clients also identified an increase in confidence and the counsellor's independent view as valuable parts of attending the service.

One client felt there was no valuable part to attending the service.

4.3.2. Were there times when you felt counselling was particularly helpful? Give examples Answers to this question focused on the benefits of transferring what they had learned in counselling to their everyday lives. Fifteen of the clients made comments which indicated that they found the counselling particularly helpful when faced with stresses in their lives. For example:

"It helps me see my problems more clearly"

"It helps me deal with my problems"

"I learnt ways of relieving stress"

"It helps me analyse my actions"

"It helped me when I thought of killing myself $(\times 2)$ ". 
Others said that counselling "made me feel happy about myself" or "it gave me confidence." The remainder repeated the comments they had made in response to question two.

\subsubsection{Did your problem change while attending the service? If yes, in what way?}

For the majority of clients, their problems have improved while attending the service. Clients reported feeling more confident (4), better able to deal with things (4) and improved relations/communication in the family (4). Other clients reported feeling calmer, less fearful, and less worried. Still others reported having more belief in themselves, feeling better about themselves and finding it easier to make friends.

Two clients felt that the underlying issue had not improved, but they felt better able to cope with things.

As we can see, the client evaluations of the service are overwhelmingly positive. They have presented for a wide variety of reasons and have benefited from being listened to and being affirmed. Counselling was particularly useful in helping clients cope with stress in their lives and this has led to an improvement in their situation while attending the service. Recommendations for the service focused on expanding the service and making it more widely known amongst young people.

\section{Discussion}

\subsection{Community-based youth counselling}

The Kildare Youth Services Youth Counselling Service is 'community-based' in the sense that it is embedded in an existing youth service. It is not a stand-alone service dedicated to the counselling needs of young people. This is perceived to be an advantage in that it is less likely to be perceived as a 'mental health' service with the associated connotations of embarrassment in the minds of the target age group. Unfortunately, mental health and counselling services in Ireland continue to carry a certain stigma. A service which can reach out to young people in their own community, which is seen as part of an existing youth service can go some considerable way to reducing this stigma. Services which are viewed as more accessible, more acceptable and more user-friendly are more likely to appeal to young people. A number of recent reports have highlighted the need for accessible, communitybased counselling services for young people (Department of Health and Children, 1999; Fleming \& Kenny, 1998; Kelleher, Keeley, \& McAuliffe, 1998; McGowan, 1997; Newbridge Community Development Group, 1998; Smith, 1998).

The need to make mental health services attractive to young people (especially young men) is an important aspect of the suicide prevention work of the National Suicide Research Foundation. Regarding young men, Kelleher, Keeley, and Corcoran (1997) wrote, "It is obvious that this group do not see the services, as presently structured and delivered, as being relevant to them" (p. 264).

\subsection{Youth and community issues in Co. Kildare}

We have seen that significant problems face adolescents and young people in Co. Kildare and, indeed, nationally. To re-cap, underage drinking in Ireland is the highest in 
Europe, suicide rates amongst young males have increased dramatically in recent years and unwanted sexual experiences amongst adolescent girls are commonplace.

Whilst only a small sample of professionals who refer to the Youth Counselling Service were interviewed, there was widespread and consistent concern amongst interviewees regarding the extent of alcohol and drug use amongst young people in Co. Kildare, early sexual activity and problems associated with family breakdown.

There is a widespread perception that community-based youth counselling services are an important method of tackling the range of concerns and difficulties that face young people. To summarise, the importance of community-based youth counselling was identified

- by the National Suicide Research Foundation Annual Report (2002)

- in the Newbridge Community Development Group (1998)

- in research examining the needs of Community Training Workshop trainees (Fleming \& Kenny, 1998)

Of course, counselling is not a panacea. Not everybody benefits from counselling. Despite dramatic claims that it changes lives, it is not always easy to quantify its contribution. In the present study, clients were asked 'What did counselling do for you?' Also, questions on the client evaluation form ask 'What was the most valuable part of attending the service?' and 'Did your problem change while attending the service?' The responses to these questions, detailed in the Results above, are perhaps the most eloquent testimony to the benefits received by adolescent and young people from having access to a friendly, accessible, community-based, free counselling service.

\subsection{Accommodation and resources}

A comparable service would be embedded and integrated in the community, perhaps using accommodation already existing for community work. The number of counsellors in the service would initially be a ratio of the population in the catchment area. For example, The Dublin Institute of Technology counselling service serves 21,000 students with 6 counsellors, the ratio being 1:3500 in this instance. A similar ratio may or may not work as well in a community setting but it would be a good starting point. Over time the needs of the community would dictate counsellor numbers. However it is important that a consistent number of full-time counsellors remain within the service.

\section{Conclusion}

This paper examined the settings and structures of a community-based youth counselling service. Given its impact with limited resources, the Kildare Youth Services Youth Counselling Service should be a model for similar projects elsewhere. It is recommended that future expansion of the Service should occur with the same principle of 'embeddedness in the community'. 
The benefits of counselling represent a very high rate of return in terms of psychological support to the community, for such a small service. It represents extraordinarily good value for money for the Health Board and the Department of Social, Community and Family Affairs (funders of the Service). The benefits of community-based counselling must continue to be recognised and should be expanded to target a greater population nationwide.

\section{References}

Alliance. (1997). What on earth are they doing? Cork: Alliance.

Brinkley, A., Fitzgerald, M., \& Greene, S. (1998). Substance use in early adolescence: A study of the rates and patterns of substance use among pupils in Dublin. Dublin: Eastern Health Board.

Department of Education and Science. (2003). National youth work development plan, 2003-2007. Dublin: Government Stationary Office.

Department of Health and Children. (1999). Youth as a resource: Promoting the health of young people at risk. Dublin: Author.

Eastern Health Board. (1999). Substance abuse in school going teenagers in Co. Kildare and West Wicklow. EHB and Action South Kildare.

Fitzgerald, M. (1997). Rural youth needs in North Offaly and West Kildare: A youth work response. Naas: Kildare Youth Services \& OAK Partnership.

Fleming, T., \& Kenny, D. (1998). Early school leaving in Mid-Kildare: A research report and review of Newbridge CTW. NUI Maynooth: Centre for Adult and Community Education.

Hibell, B., Andersson, B., Ahlström, S., Balakireva, O., Bjarnason, T., Kokkevi, A. et al. (2000). The 1999 ESPAD Report. Alcohol and other drug use among students in 30 European countries. The Swedish Council for Information on Alcohol and Other Drugs (CAN) and The Pompidou Group at the Council of Europe. Stockholm, Sweden.

Hibellm, B., Andersson, B., Bjarnason, T., Kokkeri, A., Morgan, M., Narusk, A. (1997). The 1995 ESPAD report: Alcohol and drug use among students in 26 European countries. The Swedish Council for Information on Alcohol and Other Drugs (CAN) and The Pompidou Group at the Council of Europe. Stockholm, Sweden.

Kelleher, M., Keeley, H., \& McAuliffe, C. (1998). Suicide in adolescents. Modern Medicine of Ireland, 28(1), $27-36$.

Kelleher, M., Keeley, H. S., \& Corcoran, P. (1997). The service implications of regional differences in suicide rates in the Republic of Ireland. Irish Medical Journal, 90(7), 262-264.

Kildare Youth Service. (2001). Youth counselling service: A needs assessment. Naas: Youth Counselling Service.

Kildare Youth Service. (2003). Youth counselling service annual report 2003. Naas: Author.

Lalor, K. (1999). The incidence of unwanted childhood sexual experiences amongst a sample of third level students. Irish Journal of Psychology, 20(1), 15-28.

Lalor, K., O' Regan, C., \& Quinlan, S. (2003). Determinants of sexual behaviour. Irish Journal of Sociology, $12(2), 121-134$.

MacHale, E., \& Newell, J. (1997). Sexual behaviour and sex education in Irish school-going teenagers. International Journal of STD \& AIDS, 8(3), 196-200.

McGee, H., Garavan, R., de Barra, M., Byrne, J., Conroy, R. (2002). The SAVI report: Sexual abuse and violence in Ireland - a national study of Irish experiences, beliefs and attitudes concerning sexual violence. Dublin: The Liffey Press \& Dublin Rape Crisis Centre.

McGowan, J. (1997). Youth needs in Edenderry Town and environs. Tullamore: Midland Regional Youth Council.

National Suicide Research Foundation Annual Report. (2002). Parasuicide in the Republic of Ireland. Cork: National Suicide Research Foundation.

Newbridge Community Development Group. (1998). Action plan. Newbridge: Newbridge Community Development Group.

O'Dwyer, A. (2001). In from the cold: Towards a strategy for rural youth work. Kerry: Kerry Diocesan Youth Service and The Irish Youth Foundation. 
Sarma, K., Walker, M., Ryan, W. (2002). Cigarette, alcohol and drug use among second-level students in Waterford/Kilkenny and Kerry Garda divisions. Garda Research Unit.

Smith, J. (1998). Tullamore youth needs. Tullamore: Midland Regional Youth Service.

Stapleton, M. (2000). Youth social and educational needs in Kildare Town. Kildare Youth Services \& Action South Kildare. 